\title{
In vivo effects of orally administered prednisolone on prostaglandin and leucotriene production in ulcerative colitis
}

\author{
K LAURITSEN, L STæRK LAURSEN, K BUKHAVE, AND J RASK-MADSEN \\ From the Department of Medical Gastroenterology, Odense University Hospital, Odense, Department of \\ Medicine C, Herlev Hospital, University of Copenhagen, and Department of Medicine B, Bispebjerg Hospital, \\ University of Copenhagen, Denmark
}

SUMMARY It has been proposed that anti-inflammatory actions of corticosteroids rely on promotion of a natural peptide phospholipase $\mathrm{A}_{2}$ inhibitor, lipocortin, but in vivo effects on arachidonic acid metabolism have not been shown. Equilibrium dialysis of the rectum in patients with ulcerative colitis was used to determine whether cyclooxygenase and lipoxygenase products released from the inflamed rectal mucosa could be differentially inhibited by systemic treatment with prednisolone and indomethacin, respectively. In 10 patients with severe disease luminal concentrations of prostaglandin $E_{2}$, prostaglandin $F_{2 \alpha}$, and leucotriene $B_{4}$ were markedly raised $(\mathrm{p}<0 \cdot 05)$ on comparison with 10 healthy controls, and they decreased significantly $(\mathrm{p}<0 \cdot 05)$ within 72 hours after administration of prednisolone $1.5 \mathrm{mg} / \mathrm{kg} /$ day orally. In contrast prostaglandin, but not leucotriene $B_{4}$ concentrations decreased $(p<0.05)$ within 72 hours after administration of indomethacin $150 \mathrm{mg} /$ day in another 10 patients with distal disease. These prompt reductions in concentrations of arachidonic acid metabolites more likely are caused by direct drug actions, rather than being secondary to decreased tissue damage. The data accord with the theory explaining antiinflammatory effects of corticosteroids through lipocortin activity and support the belief that leucotrienes are more important than prostaglandins as mediators of inflammation in ulcerative colitis.

Administration of pharmacologic doses of corticosteroids is one of the therapeutic mainstays in the treatment of a large number of inflammatory and immunologically mediated diseases. Despite their widespread use it has not been possible to conceptualise their anti-inflammatory mechanisms in any single model, ${ }^{2}$ although increasing lines of investigation are concerned with a modulation of the arachidonic acid cascade. Arachidonic acid is released from cellular phospholipids by the activity of various phospholipases ${ }^{3}$ and is subsequently metabolised either through the cyclooxygenase pathway ${ }^{4}$ to prostaglandins, prostacyclin and thromboxanes or

\footnotetext{
Address for correspondence: Dr Jørgen Rask-Madsen. Section of Gastroenterology, Department of Medicine B, Bispebjerg Hospital, DK-2400 Copenhagen NV, Denmark.

Received for publication 29 January 1987.
}

through the lipoxygenase pathways so hydroxyperoxyeicosatetraenoic acids, hydroxyeicosatetraenoic acids, and leucotrienes. These oxygenation products play a central role - both in the expression of the efferent limb of immune based inflammatory responses and in acute inflammatory responses where specific immunity plays no primary role $^{6}$ - by acting as mediators of pain, fever, increased vascular permeability, or oedema formation and as modulators of numerous aspects of lymphocyte and phagocytic cell function. ${ }^{7}$ Unlike aspirin and other non-steroidal anti-inflammatory compounds, which block the cyclooxygenase pathway, ${ }^{\circ}$ the corticosteroids do not inhibit arachidonic acid metabolism in cell free systems. ${ }^{89}$ In contrast, these drugs are considered to inhibit phospholipase activity in viable cells $^{11-12}$ by promoting the synthesis of a natural 
phospholipase $\mathrm{A}_{2}$ inhibitor, commonly denoted as lipocortin. ${ }^{13}$ Although this action of corticosteroids, in high doses at least, seems fairly reproducible in various in vitro systems and in some experimental models of inflammation in animals, its relevance for the in vivo condition in man remains unsettled. Furthermore, in recent studies the administration of pharmacologic doses of corticosteroids did not affect the total body prostanoid synthesis in the normal condition. ${ }^{14} 15$ We therefore studied whether cyclooxygenase- and lipoxygenase products released from inflamed rectal mucosa ${ }^{\text {th }}$ in patients with ulcerative colitis could be promptly - that is, within 72 hours, and differentially inhibited by orally administered prednisolone and the cyclooxygenase inhibitor, indomethacin, respectively. Considering the difficulties inherent in the choice of an experimental design, which prevents non-specific stimulation of arachidonic acid release and metabolism, ${ }^{17}$ we applied the method of in vivo dialysis of rectum ${ }^{16}$ to provide the most reliable index of the balance between local synthesis and degradation in vivo.

\section{Methods}

\section{SUBJECTS}

The study comprised 10 consecutive inpatients (four men and six women, aged 23-69 years) fulfilling the following criteria: (1) proven ulcerative colitis; ${ }^{18}$ (2) endoscopically proven rectal affection; (3) severe disease activity according to a conventional semiquantitative grading; ${ }^{19}$ and (4) no drug treatment, at least the last week before entry to the study. Thus current consensus indicated systemic treatment of these patients with high dose corticosteroids. ${ }^{21} \mathrm{~A}$ control group consisted of 10 (three men and seven women; aged 21-69 years) out of 12 untreated consecutive outpatients (two refused participation) with proven ulcerative colitis ${ }^{18}$ confined to the rectum and distal sigmoid colon with moderate or severe endoscopic disease activity ${ }^{19}$ and no general symptoms or signs of clinically severe disease activity. ${ }^{19}$ The conventional treatment of these patients, that is sulphasalazine and topical corticosteroids, ${ }^{20}$ was postponed by a three day prescription of indomethacin. Finally, another control group consisted of 10 healthy subjects (five men and five women; aged 16-49 years). Neither of the controls had taken any drug the week before the study. Each participant gave informed consent. The study was done in accordance with the Helsinki Declaration II and approved by the regional ethics committee.

EXPERIMENTAL DESIGN

Equilibrium in vivo dialysis of the rectum was done as recently described elsewhere: ${ }^{10}$ (1) Before and within
72 hours of treatment with oral prednisolone 1.5 $\mathrm{mg} / \mathrm{kg} / \mathrm{day}$ administered as two doses in the 10 inpatients with severe ulcerative colitis; (2) before and within 72 hours on indomethacin $50 \mathrm{mg}$ orally three times daily in the 10 outpatients with distally located ulcerative colitis. The compliance to prescription was checked by counting returned capsules of indomethacin and by the determination of serum concentrations of indomethacin ${ }^{21}$ at 72 hours; and (3) once in 10 healthy controls. To avoid tissue damage and subsequent artificial arachidonic acid release rectal biopsy specimens were not obtained until completion of the second dialysis procedure, when the patients continued treatment according to the routine of the clinic." The dialysates were analysed for the cyclooxygenase products, prostaglandin $E_{2}$ and prostaglandin $F_{2 \alpha}$, and for the lipoxygenase product, leucotriene $\mathrm{B}_{4}$.

ANALYTICAL PROCEDURES

Prostaglandin $E_{2}$ and prostaglandin $F_{2 u}$ were measured by radioimmunological methods validated by gas chromatography mass spectrometry ${ }^{22.3}$ and leucotriene $\mathrm{B}_{4}$ was measured by quantitative high pressure liquid chromatography ${ }^{16}$ as previously described.

\section{STATISTICAL ANALYSIS}

Non-parametric statistics were used. The results were given as medians with ranges. The data were analysed by the Mann-Whitney test for unpaired variates and the Wilcoxon's matched-pairs-signedranks test as appropriate. Only two tailed tests were used. Values of $p<0.05$ were considered significant.

\section{Results}

The concentrations of prostaglandins and leucotriene $B_{4}$ in the rectal lumen were markedly increased (Mann-Whitney test $p<0.05$ ) in both groups of patients with ulcerative colitis compared with healthy controls (Table). Leucotriene $\mathrm{B}_{4}$ concentrations were significantly more raised $(\mathrm{p}<0.05)$ in patients with severe disease (Table) than in patients with distally located disease. Conversely, the concentrations of prostaglandins were not different between the groups of patients.

Figure 1 shows a significant decrease (Wilcoxon's matched-pairs-signed-ranks test, $p<0 \cdot 05$ ) in luminal concentrations of cyclooxygenase and lipoxygenase products in the rectum from patients with ulcerative colitis within 72 hours of starting prednisolone treatment. The clinical condition improved gradually in all cases during the continued hospitalisation and the dose of prednisolone was gradually tapered.

During indomethacin administration luminal con- 
Table Median concentrations (range) of prostaglandins $(\mathrm{ng} / \mathrm{ml})$ and leucotriene $B_{4}(\mathrm{ng} / \mathrm{ml})$ in the rectal lumen of patients with ulcerative colitis and healthy controls

\begin{tabular}{lllr}
\hline & Ulcerative colitis & \\
\cline { 2 - 4 } & Inpatients with severe disease $(n=10)$ & $\begin{array}{l}\text { Outpatients with distally located } \\
\text { disease }(n=10)\end{array}$ & $\begin{array}{l}\text { Controls } \\
(n=10)\end{array}$ \\
\hline Prostaglandin $\mathrm{E}_{2}$ & $14 \cdot 5(7 \cdot 1-58 \cdot 3)^{*}$ & $18 \cdot 7(0 \cdot 9-87 \cdot 7)^{*}$ & $0 \cdot 4(0 \cdot 2-0 \cdot 6)$ \\
Prostaglandin $\mathrm{F}_{2 a}$ & $2 \cdot 2(1 \cdot 6-6 \cdot 9)^{*}$ & $2 \cdot 5(0 \cdot 7-8 \cdot 2)^{*}$ & $0 \cdot 2(0 \cdot 2-0 \cdot 6)$ \\
Leucotriene $\mathrm{B}_{4}$ & $7 \cdot 0(1 \cdot 7-18 \cdot 3)^{*}+$ & $1 \cdot 0(<0 \cdot 5-5 \cdot 7)^{*}$ & $<0 \cdot 5(<0 \cdot 5)$ \\
\hline
\end{tabular}

${ }^{*} \mathrm{p}<0.05$ compared with controls; $\nmid \mathrm{p}<0.05$ compared with patients with distally located disease; Conversion: traditional units to $S_{1-P G E}$, $\mathrm{PGF}_{2 a}$, and $\mathrm{LTB}_{4}: 1 \mathrm{ng} / \mathrm{ml} \approx 3 \mathrm{nmol} / \mathrm{l}$.

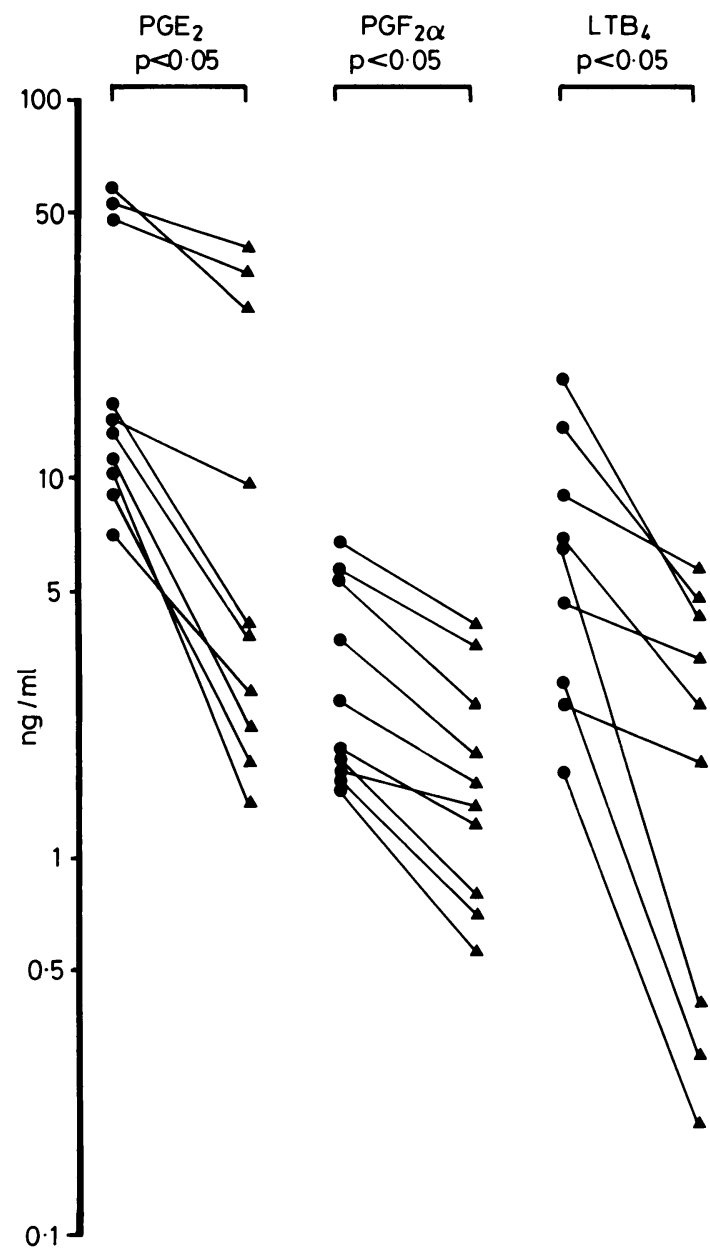

Fig. 1 Effects of prednisolone $(1.5 \mathrm{mg} / \mathrm{kg} /$ day orally) within 72 hours on luminal concentrations of prostaglandin $E_{2}\left(P G E_{2}\right)$, prostaglandin $F_{2 u}\left(P G F_{2 u}\right)$ and leucotriene $B 4$ $\left(L \mathrm{~TB}_{4}\right)$ in the rectum of ten inpatients with severe ulcerative colitis. denote pretreatment values and $\mathbf{\Delta}$ post-treatment values. Logarithmic scale. Post-treatment leucotriene $B_{4}$ analysis failed in a single case. centrations of prostaglandins decreased significantly (Wilcoxon's matched-pairs-signed-ranks test, $\mathrm{p}<0 \cdot 05)$, whereas leucotriene $\mathrm{B}_{4}$ concentrations increased in five cases, were unchanged in three, and decreased in a single patient with distally located ulcerative colitis (Fig. 2). Counting of returned indomethacin capsules was consistent with the stipulated prescription and serum indomethacin concentrations ranged from $0 \cdot 24-2 \cdot 13 \mu \mathrm{g} / \mathrm{ml}$ (median 1.01 $\mu \mathrm{g} / \mathrm{ml}$ ), showing a good compliance to the outpatient regimen. Two patients claimed nausea and one of dizziness, but no change in the bowel symptoms were reported during this short term administration of indomethacin. All patients recovered during the subsequent topical treatment with corticosteroids.

\section{Discussion}

The results show increased concentrations of prostaglandin $E_{2}$, prostaglandin $F_{2 \alpha}$, and leucotriene $B_{4}$ in the rectal lumen of patients with active inflammatory bowel disease. Although arachidonic acid oxygenation products are putative mediators of inflammation it cannot be excluded that increased amounts may simply be measurable epiphenomina of the local inflammatory process..$^{2+}$ In contrast, a decrease in disease activity and tissue damage is unlikely to have occurred within 72 hours of medication with indomethacin, which has proved ineffective in this particular inflammation. ${ }^{25}{ }^{26}$ The significantly decreased concentrations of prostaglandins in the face of rising leucotriene $B_{4}$ concentrations may, therefore, be explained by the pharmacologic action of indomethacin. In this connection the prompt reduction in concentrations of all measured arachidonic acid oxygenation products after prednisolone may also represent a direct pharmacologic action of the corticosteroid.

The in vivo demonstration of a drug induced alteration of arachidonic acid metabolism in a certain way does not necessarily indicate that the drug alters the course of inflammation via that mechanism. ${ }^{27}$ 


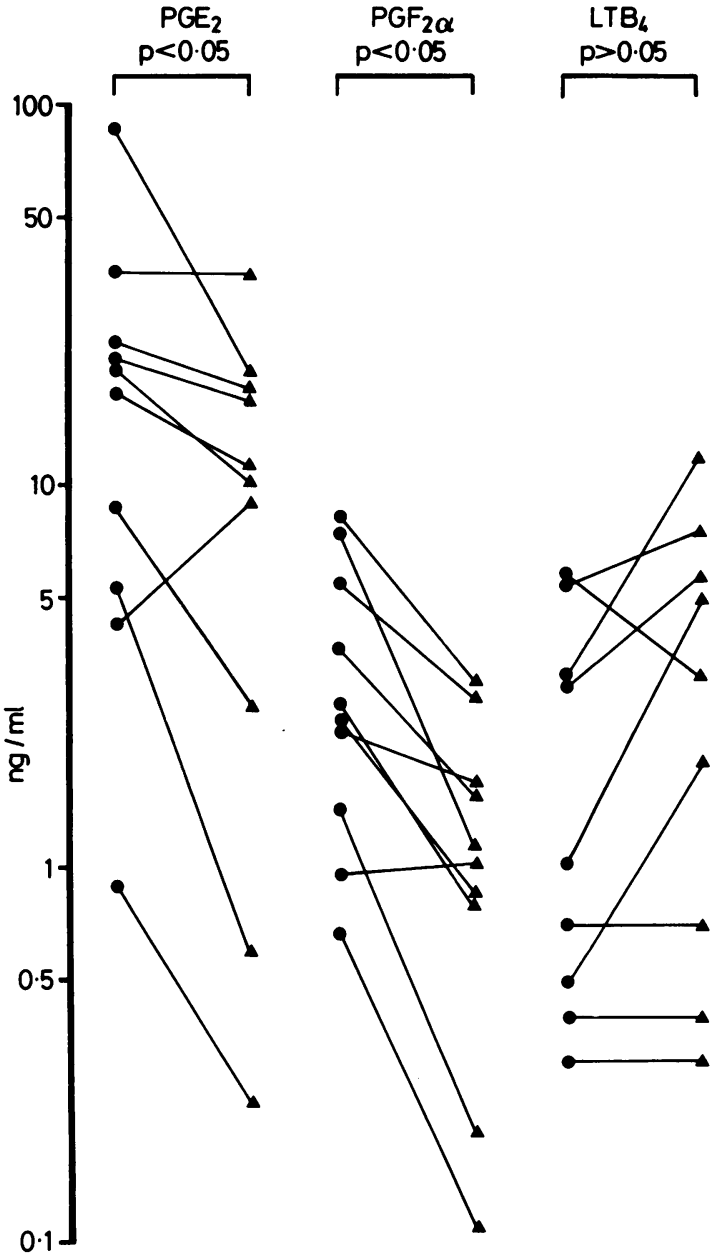

Fig. 2 Effects of indomethacin $(150 \mathrm{mg} /$ day orally) within 72 hours on luminal concentrations of prostaglandin $E_{2}$ $\left(P G E_{2}\right)$, prostaglandin $F_{2 \alpha}\left(P G F_{2 \alpha}\right)$, and leucotriene $B_{4}$ $\left(L T B_{4}\right)$ concentrations in the rectum of ten outpatients with distally located ulcerative colitis. denote pretreatment values and $\mathbf{\Delta}$ post-treatment values. Logarithmic scale. Sampling of dialysate was insufficient for $\mathrm{LTB}_{4}$ analysis in a single case.

Because corticosteroids are the most effective drugs in ulcerative colitis ${ }^{21}$ it is tempting to ascribe the antiinflammatory mechanism to the observed effect of the drug on arachidonic acid metabolites. This is consistent with the observation that leucotriene $B_{4}$ is a powerful chemotactic agent, ${ }^{2 *}$ which has been shown in increased amounts in scraped colonic mucosa from patients with ulcerative colitis. ${ }^{29}$

We have previously found that luminal concentrations of prostaglandin $E_{2}$ and leucotriene $B_{4}$ were positively correlated to disease activity in patients with distally located ulcerative colitis and decreased toward control levels at two or four weeks in the patients who had responded to treatment. ${ }^{16}$ The reports that indomethacin is without therapeutic efficacy in ulcerative colitis ${ }^{25.26}$ and the present observations of more increased concentrations of leucotrien $\mathrm{B}_{4}$ in patients with severe disease, in addition to the prompt decrease after prednisolone, substantiate the belief ${ }^{2 y}$ that leucotrienes may be more important than prostaglandins as mediators of inflammation in ulcerative colitis.

The present data on the effects of prednisolone on stimulated arachidonic acid metabolism accord with the molecular theory of an anti-inflammatory action through inhibition of phospholipase $\mathrm{A}_{2}{ }^{1(1)-12}$ mediated by lipocortin, a $40 \mathrm{kD}$ protein, the structure of which is now known. ${ }^{31}$ In addition to being derived from phosphatidylcholine and phosphatidylethanolamine by the activation of phospholipase $\mathrm{A}_{2}$, arachidonic acid is released from inositol phospholipids, via two consecutive reactions catalysed by phospholipase $\mathrm{C}$ and diacylglycerol lipase..$^{3132}$ Our data make it tempting, therefore, to suggest that phosphatidylinositol turnover is the major source of arachidonic acid in the normal condition, where total body production of prostaglandins appears unaffected by corticosteroids, ${ }^{14}{ }_{15}^{15}$ whereas the action of phospholipase $\mathrm{A}_{2}$ is a major determinant of arachidonic acid metabolism in the inflamed tissue.

This work was supported by the Danish Medical Research Council (No 12-4508), and presented, in part, at the American Gastroenterological Association meeting in New York, NY, USA 1985 (Gastroenterology 1985; 88: 1466. [Abstract]). We thank cand. pharm. Karen Møller Jensen, Dumex Ltd, Copenhagen, for determination of serum indomethacin; Mrs Anne Hallander, Mrs Inge-Lise Løffval, and Mrs Lene Persson for expert technical assistance; and Mrs Rigmor Petersen for help in preparing the manuscript.

\section{References}

1 Parrillo JE, Fauci AS. Mechanisms of glucocorticoid action on immune processes. Annu Rev Pharmacol Toxicol 1979; 19: 179-201.

2 Schleimer RP. The mechanisms of antiinflammatory steroid action in allergic diseases. Annu Rev Pharmacol Toxicol 1985; 25: 381-412.

3 Irvine RF. How is the level of free arachidonic acid controlled in mammalian cells? Biochem $J$ 1982: 204: 3-16.

4 Samuelsson B, Goldyne M, Granström E, Hamberg M, Hammerström S, Malmsten C. Prostaglandins and thromboxanes Annu Rev Biochem 1978; 47: 997-1029.

5 Hammerström S. Leukotrienes. Annu Rev Biochem 1983; 52: 355-77. 
6 Larsen GL, Henson PM. Mediators of inflammation. Annu Rev Immunol 1983; 1: 335-59.

7 Davies P, Bailey PJ, Goldenberg M, Ford-Hutchinson AW. The role of arachidonic acid oxygenation products in pain and inflammation. Annu Rev Immunol 1984; 2: 335-57.

8 Vane JR. 1971. Inhibition of prostaglandin synthesis as a mechanism of action for aspirin-like drugs. Nature New Biol 1971; 231: 232-5.

9 Lewis GP, Piper PJ. Inhibition of release of prostaglandins as an explanation of some of the actions of antiinflammatory corticosteroids. Nature $1975 ; 254$ : 308-11.

10 Blackwell GJ, Carnuccio R, DiRosa M, Flower RJ, Parente L, Persico P. Macrocortin: a polypeptide causing the anti-phospholipase effect of glucocorticoids. Nature 1980; 287: 147-9.

11 Hirata F. The regulation of lipomodulin, a phospholipase inhibitory protein in rabbit neutrophils by phosporylation. J Biol Chem 1981; 256: 7730-3.

12 Cloix JF, Colard O, Rothhut B, Russo-Marie F. Characterization and partial purification of 'renocortins': two polypeptides formed in renal cells causing the anti-phospholipase-like action of glucocorticoids. $\mathrm{Br}$ J Pharmacol 1983; 79: 313-21.

13 DiRosa M, Flower RJ, Hirata F, Parente L, RussoMarie F. Nomenclature announcement. Anti-phospholipase proteins. Prostaglandins 1984; 28: 441-2.

14 Nàray-Fejes-Toth A, Fejes-Toth G, Fischer C, Frölich JC. Effect of dexamethasone on in vivo prostanoid production in the rabbit. J Clin Invest 1984; 74: 120-3.

15 Rosenkrantz B, Nàray-Fejes-Toth A, Fejes-Toth G, Fischer C, Sawada M, Frölich JC. Dexamethasone effect on prostanoid formation in healthy man. Clin Sci 1985; 68: 681-5.

16 Lauritsen K, Laursen LS, Bukhave K, Rask-Madsen J. Effects of topical 5-aminosalicylic acid and prednisolone on prostaglandin $E_{2}$ and leukotriene $B_{4}$ levels determined by equilibrium in vivo dialysis of rectum in relapsing ulcerative colitis. Gastroenterology 1986; 91: 837-44.

17 Rask-Madsen J, and Bukhave K. The difficulties to establish the pathophysiological role of prostaglandins in secretion. In: Skadhauge E, Heintze K, eds. Intestinal absorption and secretion. Lancaster UK: MTP Press Ltd, 1984: 453-68.

18 Binder V, Both H, Hansen PK, Hendriksen C, Kreiner $\mathrm{S}$, Torp-Pedersen $\mathrm{K}$. Incidence and prevalence of ulcerative colitis and Crohn's disease in the county of
Copenhagen, 1962 to 1978. Gastroenterology 1982; 83: 563-8.

19 Binder V. A comparison between clinical state, macroscopic and microscopic appearances of rectal mucosa, and cytologic picture of mucosal exudate in ulcerative colitis. Scand J Gastroenterol 1970; 5: 627-32.

20) Riis P. A critical survey of controlled studies in the treatment of ulcerative colitis and Crohn's disease. Clin Gastroenterol 1980; 9: 351-69.

21 Jensen KM. Determination of indomethacin in serum by an extractive alkylation technique and gas-liquid chromatography. J Chromatogr 1978; 153: 195-202.

22 Bukhave K, Rask-Madsen J. Prostaglandin $E_{2}$ in jejunal fluids and its potential diagnostic value for selecting patients with indomethacin-sensitive diarrhoea. Eur $J$ Clin Invest 1981; 11: 191-7.

23 Bukhave K, Gréen K, Rask-Madsen J. Comparison of radioimmunological determinations with gas chromatography mass spectrometry dosage. A study of $\mathrm{PGE}_{2}$ and $\mathrm{PGF}_{2 \alpha}$ in gastrointestinal fluids. Biomed Mass Spectrom 1983; 10: 265-8.

24 Rampton DS, Hawkey CJ. Prostaglandins and ulcerative colitis. Gut 1984; 25: 1399-413.

25 Gilat T, Ratan J, Rosen P, Peled Y. Prostaglandins and ulcerative colitis. Gastroenterology 1979; 76: 1083.

26 Campieri M, Lanfranchi GA, Bazzocchi G, et al. Prostaglandins, indomethacin, and ulcerative colitis. Gastroenterology 1980; 78: 193 .

27 Donowitz M. Arachidonic acid metabolites and their role in inflammatory bowel disease. An update requiring addition of a pathway. Gastroenterology 1985; 88: 580-7.

28 Naccache PH, Sha'afi RI. Arachidonic acid, leukotriene $\mathrm{B}_{4}$, and neutrophil activation. Ann NY Acad Sci 1983; 414: $125-39$.

29 Sharon P, Stenson WF. Enhanced synthesis of leukotriene $\mathrm{B}_{4}$ by colonic mucosa in inflammatory bowel disease. Gastroenterology 1984; 86: 453-60.

30 Wallner BP, Mattaliano RJ, Hession C, et al. Cloning and expression of human lipocortin, a phospholipase $\mathrm{A}_{2}$ inhibitor with potential anti-inflammatory activity. Nature 1986; 320: 77-81.

31 Nishizuka $Y$. The role of protein kinase $\mathrm{C}$ in cell surface signal transduction and tumour promotion. Nature 1984; 308: 693-8.

32 Berridge MJ, Irvine RF. Inositol triphosphate, a novel second messenger in cellular signal transduction. Nature 1984; 312: 315-21. 